Cad.Est.Ling., Campinas, 47(1) e (2):109-117, 2005

\title{
ALGUMAS CONSIDERAÇÕES SOBRE O TEMA DA PONTUAÇÃO NA ESCRITA INICIAL
}

\author{
ANA CRISTINA DE AGUIAR BERNARDES \\ (Grupo de Pesquisa em Aquisição da Lingugem)
}

\begin{abstract}
This article is inspired in my doctorate thesis, whose main subject is punctuation. The interest in the issue was born in the field of early writings: texts with no punctuation at all, or, on the other hand, mysteriously punctuated, with signs showing up in slots were they were not supposed to appear. How can we apprehend this irregular punctuation? How to explain such heterogeneous punctuation episodes through the perspective of normative constraints? Children's written productions do not correspond to the adult's regularity expectations. The adult is already "immersed" in the conventions of language use and when his literate logic is projected in the child's text, a collision takes place: two distinct logics conflict and the expectations of correctness, organization, cohesion, etc. are frustrated.

In the text presented below, we discuss the theme of punctuation in regard to the field of language acquisition. Despite being a subject commonly related to proficient writing, punctuation is a very fruitful source of questions concerning the child's linguistic productions. As mentioned before, childrens' early writings are characterized by non-predictable, somewhat bizarre occurences, that oblige the investigator to suspend his/her previous knowledge and certainties about language functioning. The strangeness provoked by non-systematic uses of punctuation - or even the absence of it - will be, then, the object of our considerations in this article.
\end{abstract}

O trabalho que apresento neste evento de comemoração dos 25 anos do projeto de Aquisição de Linguagem é fruto de uma reflexão realizada em minha tese de Doutorado ${ }^{1} \mathrm{e}$ diz respeito ao tema da pontuação na escrita da criança. Falar em pontuação no contexto de um encontro em aquisição de linguagem pode soar um pouco deslocado: a pontuação é um mecanismo envolvido na prática da escrita constituída e, como tal, não estaria exatamente no escopo das discussões sobre aquisição. Mas nosso intuito é justamente trazer o tema para este universo, já que a pontuação que desponta na escrita da criança está longe de coincidir com aquela que, em princípio, diria respeito à produção escrita do sujeito já alfabetizado.

Como bem sabemos - e os dados reunidos em tantos anos de projeto confirmam isso - a fala da criança é um lugar em que os saberes constituídos sobre a linguagem - categorias, representações, classificações - são colocados em suspenso: a criança, ao começar a falar, produz enunciados insólitos, que ao mesmo tempo em que "cabem" na língua, parecem

\footnotetext{
1 "Pontuando alguns intervalos da pontuação".
} 
dela escapar o tempo todo. Há uma tensão entre estranhamento e identificação, como propõe Pereira de Castro (1997a, 1997b, 1998), ao falar sobre a relação que o adulto tem com essa língua que lhe é familiar, mas que lhe causa também desconcerto.

Semelhante raciocínio poderíamos propor para a relação do adulto com a escrita da criança: existe ali uma materialidade gráfica que ele associa com a escrita de sua língua, no entanto, as regras que norteiam o bom uso dessa escrita cedem espaço à emergência de formas gráficas mutantes, enunciados bizarros, uma pontuação absolutamente singular, enfim, arranjos que colidem com a lógica que o leitor adulto projeta sobre o texto escrito. A leitura dessa escrita inicial se dá, à semelhança do que acontece com sua fala, numa zona fronteiriça entre reconhecimento e estranhamento, entre uma transparência imaginária e uma opacidade flagrante.

A pontuação que não corresponde às prescrições normativas nos remete à questão do conhecimento, tão cara ao discurso pedagógico que envolve a entrada da criança na escrita. Justamente por ser um assunto que diz respeito às convenções de uso da linguagem escrita, a pontuação acaba sempre sendo observada sob a ótica de algo que está por vir, um conhecimento a ser construído. Este conhecimento trata de um dizer sobre a língua, uma representação acerca de seu funcionamento que inclui, dentre outras coisas, a forma como se deve pontuar. Nesta representação (da ordem do imaginário) há lugares para a pontuação - não se pontua em qualquer lugar - e há unidades previamente concebidas a serem assinaladas pelos sinais. Diremos que a pontuação obedece àquilo que Milner chama de julgamento diferencial, tal como expõe o autor:

\begin{abstract}
Podemos emitir um julgamento diferencial concernindo os dados de língua. O princípio deste julgamento diferencial é que não se pode dizer tudo. Dito de outra forma, o julgamento concerne aquilo que em matéria de língua é possível ou impossível; ele supõe, portanto, que haja um impossível de língua.

No entanto, este impossível de língua não é um impossível material. Em outras palavras, um dado de língua pode ser possível materialmente, atestado, digamos, e impossível na língua, ou inversamente. Conseqüentemente, o conjunto de dados de língua atestados e acessíveis à observação imediata se divide entre dados materialmente possíveis e lingüisticamente possíveis (coincidência entre os dois possíveis) e dados de língua materialmente atestados, mas lingüisticamente impossíveis. A atividade gramatical deverá reconhecer, dentre os dados de língua atestados, esta diferença (1989, p. 55; trad. minha)
\end{abstract}

A despeito do imaginário que se forjou ao longo dos séculos de pontuação como um expediente predominantemente normativo, o que se vê na escrita da criança, observatório que privilegiamos em nossa reflexão ${ }^{2}$, é uma grande oscilação no uso dos sinais: pontos, vírgulas, espaços em branco irrompem em lugares inesperados, produzindo segmentações e criando fragmentos que rompem com as representações prévias que se tem a respeito da organização de um texto. Noções como coesão, clareza, correção, se dissolvem diante de

\footnotetext{
${ }^{2}$ A oscilação da pontuação não é característica exclusiva da escrita da criança e o que se verifica é que nem mesmo na escrita de adultos alfabetizados há homogeneização de procedimentos para pontuar. De todo modo, nosso recorte no âmbito deste trabalho diz respeito à escrita inicial e a flutuação de pontuação que ali podemos identificar.
} 
Cadernos de Estudos Lingüísticos 47(1) e (2) - Jan./Dez. 2005

uma pontuação cuja característica mais marcante está na opacidade de uma lógica que não conseguimos rastrear com os códigos normativos.

Observar a pontuação na escrita da criança nos permite, pois, olhar para a questão da continuidade/descontinuidade, tema da mesa-redonda na qual este trabalho se insere. Os dois termos que servem de mote às reflexões colocam em cena uma série de possibilidades de abordagem do tema da pontuação, essencialmente em função dos efeitos que ela promove no texto.

Pontuar é, paradoxalmente, produzir descontinuidade e continuidade. Ao se inserir graficamente na cadeia sintagmática, a pontuação opera cortes e assim, rompe a continuidade de uma justaposição interminável de termos; sua inserção gera pedaços, porções de texto. Mas a descontinuidade que se instala na cadeia acaba por promover também uma continuidade, quando produz efeito de textualidade. $\mathrm{O}$ texto pontuado adquire uma organização singular de seus constituintes, ele não se constitui num encadeamento $a d$ infinitum. Vejamos o que nos diz Orlandi referindo-se ao par completude/incompletude:

[...] a pontuação serve para dar uma dimensão ao discurso no espaço textual. O texto dimensiona, por assim dizer, o discurso, e a pontuação é um de seus "instrumentos". Ao mesmo tempo em que é um mecanismo de espacialização dos sentidos na superfície do texto - e como, do ponto de vista discursivo, nunca temos o completo porque não podemos esgotar os sentidos - a pontuação é uma violência simbólica necessária: um mecanismo que administra nossa relação à incompletude da linguagem (Orlandi, 1983), trabalhando a incompletude do sentido e o inacabamento do sujeito. É o espaço simbólico das relações de sentidos que é pontuado. [...].

A pontuação serve assim para marcar divisões, serve para separar sentidos, para separar formações discursivas, para distribuir diferentes posições dos sujeitos na superfície textual. Elas indicam modos de subjetivação. (2001, p. 116)

No caso da escrita inicial, porém, a descontinuidade gerada pela pontuação promove, muitas vezes, efeito de ruptura, como se algo ficasse em aberto: a pontuação que emerge no texto da criança não preenche os lugares pré-determinados pelo saber gramatical. Há um descompasso com as marcações antecipadas pelo adulto alfabetizado, imerso no saber gramatical e que percebe a pontuação tal como percebe a língua - um conjunto de unidades discretas: palavras, frases, etc. - ou seja, uma percepção inexoravelmente atravessada por um dizer sobre a língua. Ali onde ele espera que haja pontuação, ela não aparece e, ao contrário, ali onde não deveria haver pontuação, ela irrompe, inusitada. A pontuação que emerge no texto da criança expõe o impossível de língua, tal como o define Milner (1989), em citação anterior: pontos, vírgulas e outros sinais surgem em lugares da cadeia sintagmática onde não seria possível inseri-los, no entanto, eles estão ali, materialmente atestados.

A diferença entre a pontuação da criança e a pontuação do adulto que lê seu texto traz à tona uma colisão de imaginários em relação à escrita, na base da qual está "o caráter irreversível da transformação que se opera em nós pelo simbólico", como diz Cláudia Lemos. E a autora prossegue, lembrando-nos que "uma vez transformados pela escrita em alguém que pode ler ou escrever, não é possível subtrairmo-nos a seu efeito ${ }^{3}$, nem concebermos qual é a relação que aquele que não sabe ler tem com esses sinais que, para

${ }^{3}$ Essa observação deve ser relacionada com o que E. Orlandi (1990) tem definido como injunção à interpretação. (Nota da autora, op. cit., p. 17). 
nós, apresentam-se como transparentes. Ou ainda, não podemos mais recuperar a opacidade com que esses sinais antes se apresentavam também para nós." (1998, pp. 16-17)

A pontuação da criança situa-se num intervalo entre saber e não saber, um espaço cujas fronteiras são difíceis de precisar. Ao pontuar seu texto, ela tanto erra quanto acerta, o que muitas vezes, aliás, nos leva a supor ali uma relação de conhecimento. Mas o que ela efetivamente sabe sobre a pontuação quando começa a escrever? É fato que a atividade de escrever em sala de aula já traz consigo os efeitos do discurso normativo, mas será que, ao pontuar seus textos iniciais, a criança já está em busca da regularidade prevista para o uso dos sinais? Será que a pontuação se apresenta para ela da mesma forma que se apresenta para o adulto alfabetizado?

No trabalho de tese que inspira este artigo, analisamos alguns dados singulares de pontuação que desafiam a regularidades dos usos estabelecidos nos manuais gramaticais.

$$
\text { DA : LAURA : PARA : A : VOVÓ : }
$$

Salta aos olhos a profusão de dois pontos, inseridos entre cada palavra; o que faz com que L. pontue cada um desses espaços em branco? De acordo com Rocha (1994), em tese sobre a aquisição da pontuação, este seria um dado relativo à dificuldade inicial da criança para lidar com a alternância entre pleno e vazio; conforme explica a autora,

\footnotetext{
O espaço deixado entre as palavras é um espaço negativo. Ele é o pano de fundo. As palavras é que são inseridas nele e não o contrário. Assim, o fracasso da criança em deixar espaços entre as palavras não deve ser tomado apressadamente como um indicativo de que ela não saiba que as palavras existem como unidades separadas. Deixar espaços é um procedimento altamente abstrato para a criança manejar. Muitas delas preferem, por exemplo, inserir pontos entre palavras, que deixar espaços, o que parece indicar uma preferência pelo espaço positivo (p. 7).
}

Rocha sugere que haveria uma predileção, por parte da criança, pelo espaço positivo, ou seja, preenchido. Mas esta nos parece uma hipótese controversa, sobretudo porque, na escrita inicial, não há padrões que se repetem: ora a criança "superpontua" os espaços em branco, ora alterna entre preenchimento e não preenchimento, e ora escreve sem pontuar nenhum desses espaços, deixando-os todos vazios; como então estabelecer uma tendência ou mesmo uma preferência pelo preenchimento?

Dificilmente poderíamos rastrear a razão desse movimento de pontuação: mesmo que tivéssemos acesso à fala da criança sobre sua pontuação (à semelhança dos registros expostos no trabalho de $\mathrm{Caddé}^{4}$ ), ainda assim não poderíamos tomá-la como explicação para o que ela escreve, pois a relação do sujeito com a linguagem não é transparente e o acontecimento de escrita se apaga, ou seja, há que se contemplar a pontuação da criança em sua "desrazão" gráfica, valendo-nos aqui do belo termo empregado por Christin, no título de sua obra L'image écrite ou la déraison graphique (2001).

${ }^{4}$ CADDÉO, S. "L'usage de la ponctuation chez les enfants". In: DEFAYS, ROSIER \& TILKIN (Éds.) ̀̀ qui appartient la ponctuation? Actes du colloque international et interdisciplinaire de Liège (13-15 Mars 1997). Bruxelles: Duculot, 1998. p. 255-273. 
Cadernos de Estudos Lingüísticos 47(1) e (2) - Jan./Dez. 2005

A abundante pontuação da dedicatória de L. expressa um movimento da criança na linguagem: ela desenha, pontua, escreve, e sua produção inicial é marcada por uma cifragem impermeável à concepção utilitária de texto escrito. A escrita de L. mostra uma identificação imaginária ao universo gráfico/visual; ela pontua, e pontua, e pontua, porque está dominada, possuída pelo ato de desenhar os dois pontos, numa alusão ao que propõe A. Malraux, dizendo que a criança não possui seu talento, é seu talento que a possui. (apud Chemama, 1991, p. 16-17).

Os dois pontos que afloram na dedicatória de L. pontuam sua escrita, mas não têm valor de pontuação enquanto expediente da ordem da convenção; é porque está esvaziada de conteúdo normativo que a pontuação pode preencher todos os espaços em branco. Não há sequer vestígios de busca pela regularidade porque não há estranhamento, todos os espaços são igualmente pontuáveis, não há diferença.

Não há conhecimento formal no uso que a criança faz da pontuação em sua escrita inicial, o que não a impede, contudo, de estar sob os efeitos deste universo gráfico/visual. Isto nos leva a citar aqui a pergunta formulada por Chemama: “[...] o leitor não pode deixar de considerar que uma interrogação primordial poderia aqui constituir um ângulo de questionamento um pouco mais vivo [...]: não sobre o que ocorre com os desenhos, mas com o fato de “que se desenhe'?” (1991, p. 19; itálico do autor). O autor nos fala que as chaves do mundo no qual a criança nasce pertencem ao Outro enquanto universo discursivo, em última instância, à própria linguagem, e a passagem ao desenho deve ser situada em relação a este Outro todo poderoso. Para ele, mais do que a dependência a um universo discursivo, o que está em jogo aí é a difícil separação do corpo do Outro; o autor então pergunta: "Se o desenho pode ser para a criança fonte de júbilo [...] não seria porque constitui uma das vias privilegiadas por onde o pequenininho pode separar as formas, desembaralhar as figuras?" (p. 20).

A hipótese de Chemama nos possibilita olhar para a pontuação/desenho de L. como um movimento de subjetivação, ou seja, ao mesmo tempo em que o desenho se constitui num lugar de separação de formas - separando assim a criança do corpo do Outro - ele é também um espaço em que L. emerge como sujeito em seu texto: no movimento de repetir os dois pontos e inseri-los em todos os intervalos entre as palavras, algo de sua relação singular com a linguagem se atualiza nesse insistente preenchimento do espaço em branco.

A propósito da repetição, aliás, vejamos o que nos diz Barthes:

Este tipo de escrita [os entalhes, as marcas, as séries de nós, de objetos, etc.] liga-se à fabricação dos objetos; a técnica de fabricação situa-se numa 'atmosfera' rítmica, visto que consiste num longo e regular martelar, numa técnica muscular, auditiva e visual, que produz o objeto pela repetição de gestos. Foi precisamente a inscrição desta repetição no corpo como ritmo pulsional que fez nascer a idéia de domesticação do real: a repetição é o meio de simbolizar o eterno retorno de significantes naturais: assim o domínio da ritmicidade natural permite integrar numa rede simbólica o regresso das estações, das horas, dos frutos, dos nascimentos; a ritmicidade controlada dos passos permite a simbolização das distâncias. (1987, p. 35).

O autor refere-se aos primórdios da atividade escrita, mas fala da repetição enquanto “domesticação do real”, um movimento que poderíamos vislumbrar na pontuação de L; é 
como se a repetição dos dois-pontos lhe permitisse também "domar" o espaço gráfico, sem que isso represente, porém, uma tentativa consciente de apreensão das regras de seu funcionamento. A dedicatória de L. é, pois, emblemática da reflexão que empreendemos sobre a pontuação na escrita inicial, contemplando-a como um fazer da criança na linguagem e não como uma atividade metalingüística orientada para a construção de um conhecimento.

$\mathrm{O}$ texto que transcrevemos a seguir também nos permite algumas indagações pertinentes ao que vimos discutindo:

\section{"Os pescadores mal."*}

Era uma, ves 8 pescadores que éram muimto, maudosos que estavam acabando com os pexes (.)• do mar um dia o dono, do mar e a sua esposa fiseram uma, reuniam com os pexes do mar que não subir na flor da agla e as conxinhas não ir para a pranha e as ondas e as omdinhas não ir para a pranha ape ele mãendar elas e o povo veio reclamãendo cade os meus filhos e a raia falándo so chove anjol em mim agora vanos para as suas casas pasou 131 dias e depois desetenpem de ferias vanos trabanhar e os pescadores pegaram bastante pexes mais os 8 pescadores mal não pegaram nenhum pexe e comtinuou assim e $o$ pescadere ficaram felises para sempre e os pexes também e as plentas do mar.

De onde surgem as vírgulas em "Era uma, ves"; "muimto, maudosos"; "dono, do mar";"uma, reuniam"? É curioso que todas elas sejam inseridas em lugares bastante impermeáveis à entrada de uma marca de pontuação, o que acentua o efeito de ruptura. Este raciocínio, porém, parte de uma observação atravessada pelo saber sobre o funcionamento da língua e as regras que determinam, dentre outras coisas, a adequação, ou não, de certas ocorrências de pontuação.

Mas a assistematicidade da pontuação da criança, que transita livremente pelo texto, nos obriga a suspender esse saber, pois ele não coincide com as representações prévias que temos a respeito dos "pontos de pontuar". Nesse movimento de suspensão, postulamos que a criança, ao começar a escrever, está colada a um imaginário sobre a escrita no qual os sinais de pontuação têm valor puramente gráfico/visual e não estão preenchidos com valor normativo, ou seja, haveria uma continuidade entre letras, pontos, traços, etc., numa relação de semelhança. Não há dessemelhança entre o alfabeto e os sinais de pontuação e a criança não os percebe, portanto, como um sistema que se sobrepõe à escrita, numa relação de diferença.

* O texto é extraído de Aguiar, Dissertação de Mestrado, IEL, Unicamp, 1995. Transcreve-se o conteúdo e a disposição gráfica do original.

- Parece haver um ponto neste lugar, mas não está claro no original. 
Cadernos de Estudos Lingüísticos 47(1) e (2) - Jan./Dez. 2005

É oportuno salientar que, ao nos referirmos à noção de imaginário e à idéia de identificação imaginária, falamos do lugar da representação, o lugar em que se coloca a suposição "o semelhante existe", de acordo com Milner. Diz o autor:

[...] No que diz respeito à existência do semelhante, concluiremos que existe o dessemelhante, e daí, que existe a relação, visto que é suficiente que dois termos sejam tomados como semelhantes ou dessemelhantes para que entre eles uma relação seja definível. Concluiremos na sequiência que existem propriedades, já que é suficiente que haja uma relação entre dois termos para que uma propriedade comum possa ser construída por abstração. Concluiremos igualmente que existem classes e que elas são fundadas sobre propriedades, que as propriedades não são senão uma maneira de construir o semelhante, que há todos e que eles têm um limite, cada todo sendo suspenso no ponto onde surge um dessemelhante. Concluiremos enfim que existe o representável, dado que a representação não supõe nada além da semelhança e da relação (1983, p.8; trad. minha).

A adesão imaginária à qual a criança submetida é marcada pela continuidade, pela similitude. Os sinais de pontuação adentram o texto como elementos de um objeto escrito que se apresenta para a criança como um todo, ou seja, há uma imagem de texto da qual os sinais não se destacam enquanto pontuação. Ao pontuar, ela está sob os efeitos desse imaginário, daí a flutuação dos sinais no texto, sua "aparição" em qualquer ponto da cadeia sintagmática, tal como em "uma, reuniam", por exemplo. Este, embora seja um dado materialmente atestado, não é um dado lingüisticamente possível, do ponto de vista das prescrições normativas. A inserção da vírgula entre os dois termos produz um efeito de ruptura, decorrente dessa disjunção entre os dois possíveis, que mencionamos anteriormente.

Em suma, a pontuação da criança não obedece à lógica dos cortes operados pelo adulto na cadeia sintagmática. Como dissemos anteriormente, citando de Lemos, o adulto alfabetizado já não consegue mais se subtrair ao efeito de um dizer sobre a língua que prevê a existência de letras, palavras, frases, parágrafos e sua lida com a linguagem está inevitavelmente impregnada dessas diferenças. A pontuação da criança, por sua vez, não responde à demanda de um julgamento diferencial: não há sequer diferença para que possa se instaurar uma partição de tipo correto/incorreto, por exemplo. Sendo assim, diríamos que a pontuação na escrita inicial não corresponde a uma busca por regularidade.

Por este motivo julgamos questionáveis as hipóteses que se baseiam na idéia de que a criança pontua de forma assistemática porque ainda não tem um saber sobre as regras da pontuação $0^{5}$. Os estudos que tentam buscar em sua pontuação uma lógica voltada para o acerto no uso dos sinais projetam nos dados um raciocínio de julgamento diferencial. Mas a escrita da criança frustra inexoravelmente a previsibilidade da regra: há episódios cuja lógica está para sempre perdida; é o lugar da contingência, da ocorrência singular, que não se deixa apreender por representações prévias.

Mas a pontuação não é a mesma depois de atravessada por aquilo que se diz sobre ela, motivo pelo qual sua entrada no texto da criança não é incólume: aquilo que a criança ainda não reconhece como diferença, mas que é capturado pelo olhar do adulto como tal, é um motor em potencial de deslocamentos, visto que o estranhamento causado pela

${ }^{5}$ Remeto o leitor aos trabalhos citados em minha tese de Doutorado, "Pontuando alguns intervalos da pontuação" (cf. referências bibliográficas). 
pontuação heterogênea no leitor adulto - já imerso na naturalidade das convenções - põe em curso um movimento de interpretação que faz reverberar os efeitos da pontuação. É por meio desta reverberação que a pontuação pode adquirir outros significados e então se submeter às restrições normativas.

Nesse sentido, inspiramo-nos na reflexão empreendida por Pereira de Castro, em seus trabalhos a respeito da aquisição da língua materna (cf. 1997a, 1997b, 1998). A autora define a interpretação como "efeito da fala do adulto na fala da criança e reciprocamente" e prossegue dizendo que "o movimento interpretativo da mãe faz-se em tensão entre uma identificação ou reconhecimento de uma língua, de um determinado universo discursivo do que the soa como familiar, e um estranhamento provocado pelos deslocamentos causados pelos movimentos da língua e que dão lugar a enunciados insólitos, arranjos desconcertantes entre os significantes incorporados" (1997a, p.4).

Pereira de Castro concentra sua reflexão na questão da aquisição da linguagem oral e os arranjos a que se refere dizem respeito à incorporação, pela criança, de significantes da fala do adulto, e da desestruturação que a interpretação deste último promove nesses enunciados tantas vezes insólitos. Podemos supor o mesmo movimento proposto pela autora para o processo de aquisição de escrita, já que este não acontece à margem da oralidade, como se fosse uma outra língua. Ao mesmo tempo em que o adulto identifica na escrita da criança a escrita de sua língua - e por isso lê "uma, reuniam" sem que isso lhe impeça de entender o que está escrito - ele também estranha algo que não se encaixa em suas representações concernindo os lugares em que se pode pontuar; há uma colisão entre a pontuação da criança e aquela antecipada pelo adulto com base nas regras de bom uso da escrita. Aos seus olhos, a irrupção da vírgula entre "uma" e "reuniam" produz uma quebra - parte-se ao meio um sintagma que não pode ser partido - mas este efeito não se produz para a criança, que não identifica aí uma descontinuidade.

Todavia, o texto pontuado cria uma leitura e a inserção da marca de pontuação produz efeitos. O efeito de estranhamento diante de uma vírgula "impossível" obriga um movimento de reconfiguração que se realiza simultaneamente ao processo de interpretação. Portanto, o ponto de ruptura pode criar uma brecha na identificação imaginária à qual a criança está submetida e assim, se constituir em motor de deslocamentos. Neste "ponto de pontuação" a interpretação pode vir a desfazer a continuidade da adesão imaginária e então agregar um novo sentido aos sinais, possibilitando uma restrição de sua flutuação no texto. Dito de outra forma, a interpretação permite que a pontuação se resignifique e assuma novos valores no texto. A restrição não resulta, portanto, de uma instrução, mas do próprio processo de resignificação empreendido pela interpretação.

A pontuação da criança não fica, pois, à margem da leitura que o outro realiza de sua escrita, ou seja, a despeito de sua heterogeneidade, ela é submetida às restrições simbólicas pelo movimento interpretativo do adulto. Não é, portanto, a exposição da regra que fará com que a criança pontue seu texto mais ou menos corretamente: isto seria imaginar a transparência na relação do sujeito com a linguagem, algo que os dados singulares nos permitem contestar. As fórmulas tradicionais às quais já estamos tão habituados - a vírgula marca uma pausa, o ponto marca a completude de uma idéia, o travessão sinaliza o discurso direto, etc. - se desfazem na escrita inicial, o que acaba por colocar em suspenso, conseqüentemente, as unidades que previamente representamos na constituição de um texto. 
Por isso entendemos que falar de pontuação na escrita inicial nos permite elaborar reflexões que concernem à questão da própria aquisição de linguagem: o ideal de transparência na relação com a linguagem e seu funcionamento, a projeção, na escrita e na fala da criança, das categorias, partições e segmentações que dizem respeito à fala e à escrita já constituídas, a identificação de um dizer sobre a língua com a língua em si e todas as suas possibilidades de equívoco, de ambigüidade, enfim, a pontuação traz à tona indagações importantes para aqueles que se interessam em investigar este funcionamento lingüístico que escapa à lógica do adulto, com todos os julgamentos diferenciais que a ela estão aderidos.

\section{REFERÊNCIAS BIBLIOGRÁFICAS}

BARTHES, R. (1987). Oral/Escrito - Argumentação. In: ROMANO, R., DIR. Enciclopédia Einaudi. Lisboa, Imprensa Nacional/Casa da Moeda. Volume 11.

BERNARDES, A.C.A. (2002). Pontuando alguns intervalos da pontuação. Tese de Doutorado, IEL, Unicamp, Campinas.

CHEMAMA, R. (1991). O ato de desenhar. In: TEIXEIRA, A. R. (org.) O Mundo a Gente Traça, Ágalma.

DE LEMOS, C.T.G. (1998). Sobre a aquisição da escrita: algumas questões. In ROJO, R. (org.) Alfabetização e Letramento. Campinas: Mercado de Letras.

MILNER, J.C. (1989). Introduction à une science du langage. Paris: Éditions du Seuil, Novembre. (1983). Les noms indistincts. Paris: Éditions du Seuil, Mars.

ORLANDI, E.P. (2001). Discurso e Texto. Formulação e Circulação dos Sentidos. Campinas: Ed. Pontes.

PEREIRA DE CASTRO, M.F. (1998). Língua materna: palavra e silêncio na aquisição de linguagem. In: Junqueira Fo. (org.) Silêncios e Luzes - Sobre a experiência psíquica do vazio e da forma. Casa do Psicólogo, São Paulo. (1997a). A interpretação: a fala do outro e a heterogeneidade da fala da criança. In: Revista L.E.T.R.A.S, $n^{\circ} 13$ (Revista do Mestrado em Letras da UFSM).

(1997b). Sobre a interpretação e os efeitos da fala da criança. In: Anais do IV Encontro Nacional de Aquisição de Linguagem.

ROCHA, I.L.V. (1994). Aquisição da pontuação: usos e saberes de crianças na escrita de narrativas. Tese de Doutorado - PUC/SP, São Paulo. 